Uganda, Kenya, Tanganyika, Zanzibar and Southern Rhodesia, and therefore may be considered as fairly representative of the sources of food for tsetse in East Africa. Similar studies in the Belgian Congo also show the overwhelming importance of warthogs and bush-pigs as a source of food.

A recent report by A. G. Robertson and J. P. Bernacca, of the Tsetse Control Department, Uganda, contains a description of the measures taken to control the southward advance of G. pallidipes, which is said to be associated with seasonal largescale southward movements of buffalo. The active control measures introduced include the development of game elimination, coupled with fierce late-burning and intensive pig-hunting. The hunting measures included the killing of all the ungulate game animals, except giraffe and roan antelope, which are very rare, and in some areas, the Uganda cob. Whilst there may be some reason for the destruction of wild pigs there would seem to be little if any justification for the widespread destruction of all ungulate game animals since many species are rarely, if ever, bitten by tsetse.

\title{
THE KARIBA LAKE
}

\section{By Reay H. N. Smithers \\ Director, National Museums of Southern Rhodesia}

On 3rd December, 1958, the two ports in the Kariba Dam, through which the whole volume of the great Zambesi River was then flowing were closed. This heralded not only a major step in this vast engineering project but also the commencement of the greatest environmental upset ever to befall a population of animals and birds within the African continent, in the memory of man.

The lake so created along the border between Northern and Southern Rhodesia will, by 1961, be by far the largest artificial body of water anywhere in the world, and will have a surface area of some 2,500 square miles. It is as though water stretched from London to York with a maximum width of 35 to 40 miles. The area of this lake will equal that of Devonshire.

Because of the nature of the Zambesi Valley, flat and wide with innumerable rocky kopjes and hills, the process of flooding will, over the next two years, produce many islands. Some will disappear under the rising waters; others will become permanent land, from a few acres to some 1,600 acres in extent. The great 
riverine forests of the Zambesi with their hinterland of rich vegetation on deep alluvium will disappear for ever. There can be no regeneration of them on the lake shore for the water will be banking up on rocky mopane country. Such re-deposit of silt as may occur will be confined to the inlet to the lake and to the mouths of the larger rivers draining into it.

Because of the richness of its vegetation and the ample shelter and water available, the Zambesi Valley has not only been a suitable habitat for a heavy population of the larger wild animals, but has also acted as a highway up which many smaller animals and birds have found their way from the low country of Portuguese East Africa deep into the heart of the dry inhospitable country lying westwards. This highway is now cut forever and the rising waters, now far above the highest flood level of normal years, have isolated large numbers of animals on the new islands. Zebra, kudu, buffalo, impala, bushbuck, klipspringer, duiker and Sharpe's steinbok, to name only a few, have already been trapped and, among the smaller animals, baboons and vervet monkeys, porcupines and ant bears, many species of cats and mongoose, squirrels and rock rabbits. Moreover the ground so far flooded is by no means the part of the valley richest in wild life.

The problem of rescuing these animals is enormous. By early November, 1958, the Southern Rhod'sia Game Department had four rangers at work with two boats and these have done magnificent work. A more suitable boat is now being provided, but obviously much more is needed, and from the Northern Rhodesia bank also, if anything really effective is to be done.

The work is hazardous. Added to the dangers of submerged stumps and floating debris, and injury from the struggles of the captured animals, there are crocodiles in the water and an unprecedented concentration of snakes on the islands. The first boats, although suitable for river conditions, are unsuitable for a lake already some 100 miles long and in places 15 miles across. It is subject to violent storms which, within minutes, whip up waves large enough to be a hazard to small boats.

This rescue undertaking, now popularly known as "Operation Noah", had already rescued by February, 1959, some 300 animals, the largest species so far handled being impala. Many novel techniques have been evolved but in general it is found that the best plan is to get the animals into the water and then either capture them or guide them swimming to the mainland. Some surprising observations have been made. Baboons and vervet monkeys not only swim well but are also capable of 
diving and swimming for considerable distances under water. Most of the animals, including warthog and bushpig, swim well, but many of the smaller kinds, notably rock rabbits and squirrels, swim poorly and in fact the latter succumb very quickly in this strange element unless rescued promptly. Bushbuck take to the water readily but it has been found virtually impossible to get impala into the water. When cornered, they turn on the beaters and either charge through their ranks or jump over their heads. Game nets, therefore, have to be used. The smaller buck such as the duiker and Sharpe's steinbok are reasonably easy to handle, but in all cases tranquilizers are being used to lessen the shock of handling and to make transport easier.

Although most of the animals swim well, they show no signs of moving from the islands of their own free will, but hold tenaciously to their rapidly dwindling points of land, sometimes until they are so emaciated that they cannot swim to safety even if driven into the water.

Rescue operations of the larger animals, such as elephant and buffalo, are out of the question and this applies equally to the dangerous predators, lion and leopard, but all these are recorded in other parts of Africa as swimming well and can probably look after themselves. It is not known how rhinoceros will behave, but experience in the Nile Valley, where both the white and black rhinoceroses occur on either side of the river without mixing, point to an aversion to water.

It has been suggested that attempts should be made to drive the animals from high ground to safety before the flood reaches them, but the broken nature of the country, and the thick bush, much of it impenetrable senanga, or thorn scrub, would render such an undertaking impossible except perhaps in very restricted areas. Even if successful, constant watch to prevent the animals' return would be necessary.

Already many islands have formed and many have disappeared under water. Where baboons and monkeys have been stranded the tops of islands remaining above water present a scene of complete desolation, with every scrap of grass eaten and every stone turned and turned again in search of insects. The supply of edible fruits has long since been exhausted and the unnatural diet causes such quick weakening of the animals that some baboons can scarcely run a dozen steps without falling over.

It is surprising to find rock rabbits (hyrax), their islands completely under water, perched on the tops of trees and it provides a great deal of personal satisfaction to catch them in a landing net and transport them safely to the mainland. Some of 
these have been marooned in the trees for periods up to four weeks yet they appear quickly to recover from their initial daze and run off among the rocks to safety. A genet cat, cut off on the top of a large baobab tree, was observed to have deposited its scats in a heap at the junction of a thick branch, as was its habit in more normal surroundings. These scats contained fish scales and one wondered how and at what stage the genet had managed to catch the fish.

It was originally thought that the birds could look after themselves, and, while this holds good for the stronger flying species such as turtle doves, many of the sedentary species such as robins, waxbills and babblers are holding tenaciously to their inundating islands. Many are now so emaciated that a flight to the mainland, which may be any distance up to several miles, is out of the question. Even when driven off the islands these birds tend to return to them. Guinea fowl and francolin too are suffering a similar fate and examination of specimens show a degree of emaciation which makes it surprising that they are still alive. Where these and other birds are marooned with small predators, or even baboons or monkeys, they are falling a prey to them. When in good condition guinea fowl driven into the water swim quite well.

Rescued animals are, as far as possible, being put on the Southern Rhodesia side of the lake where the Government has recently set aside two large areas as game reserves, the Sijarira and the Matuziadona. In time they will be open to visitors. Both these reserves have populations of black rhinoceros, not present in our Wankie National Park. Both reserves are well watered and have major tributaries of the Zambesi flowing through them. They are therefore quite fitted to absorb such animals as may be saved in "Operation Noah" and ecologically suitable for any of the species driven or transported to them.

Besides the opportunity for humanitarian effort, there exists in this major environmental upheaval, one of the most interesting research opportunities that has existed in Africa for many years. It is not being exploited to the full. At the moment and for the next two years there will be a chance to undertake unique studies in the lake area and Universities, or other bodies, should see their way to exploit this chance, for it will not occur again. 


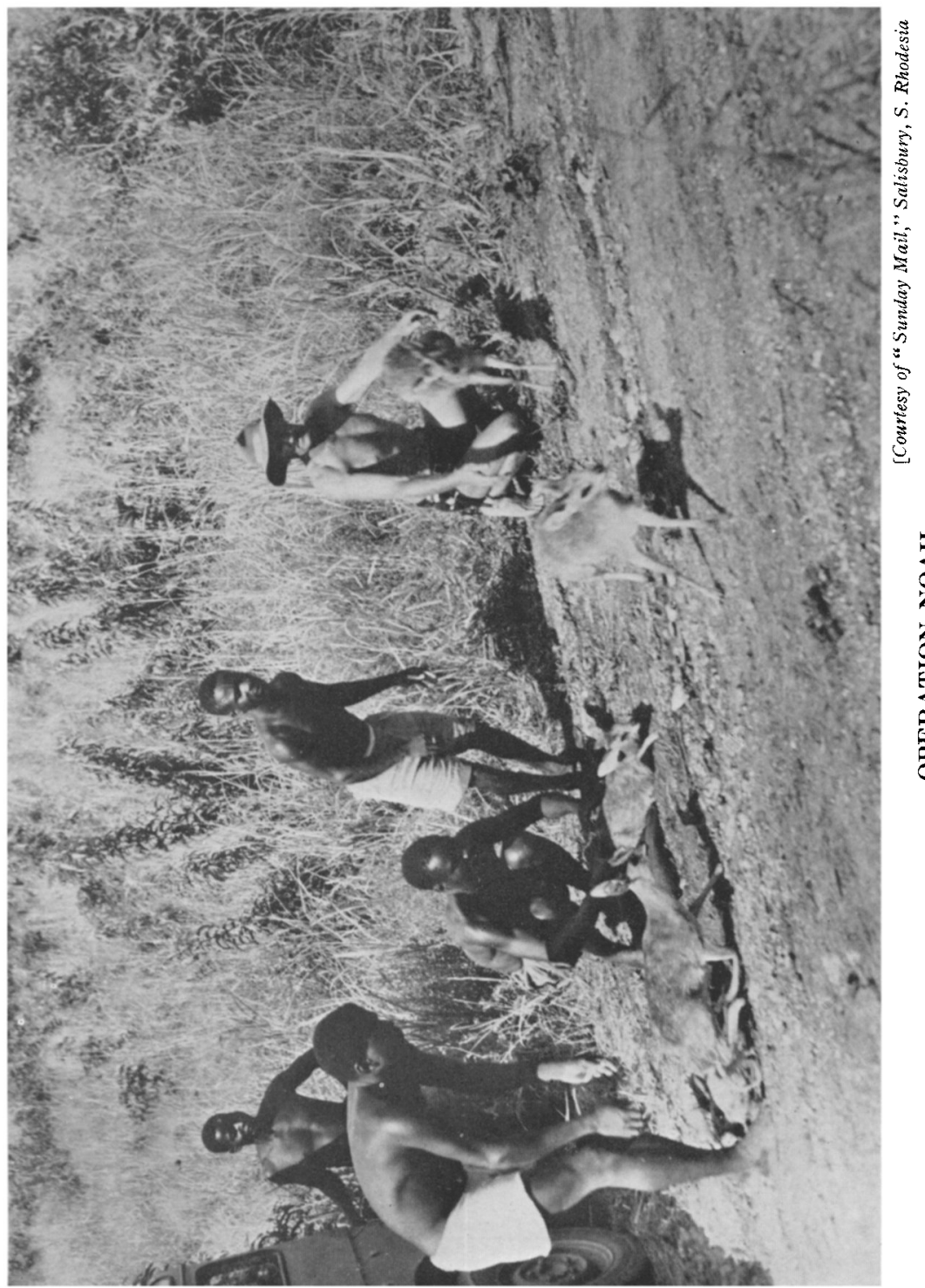




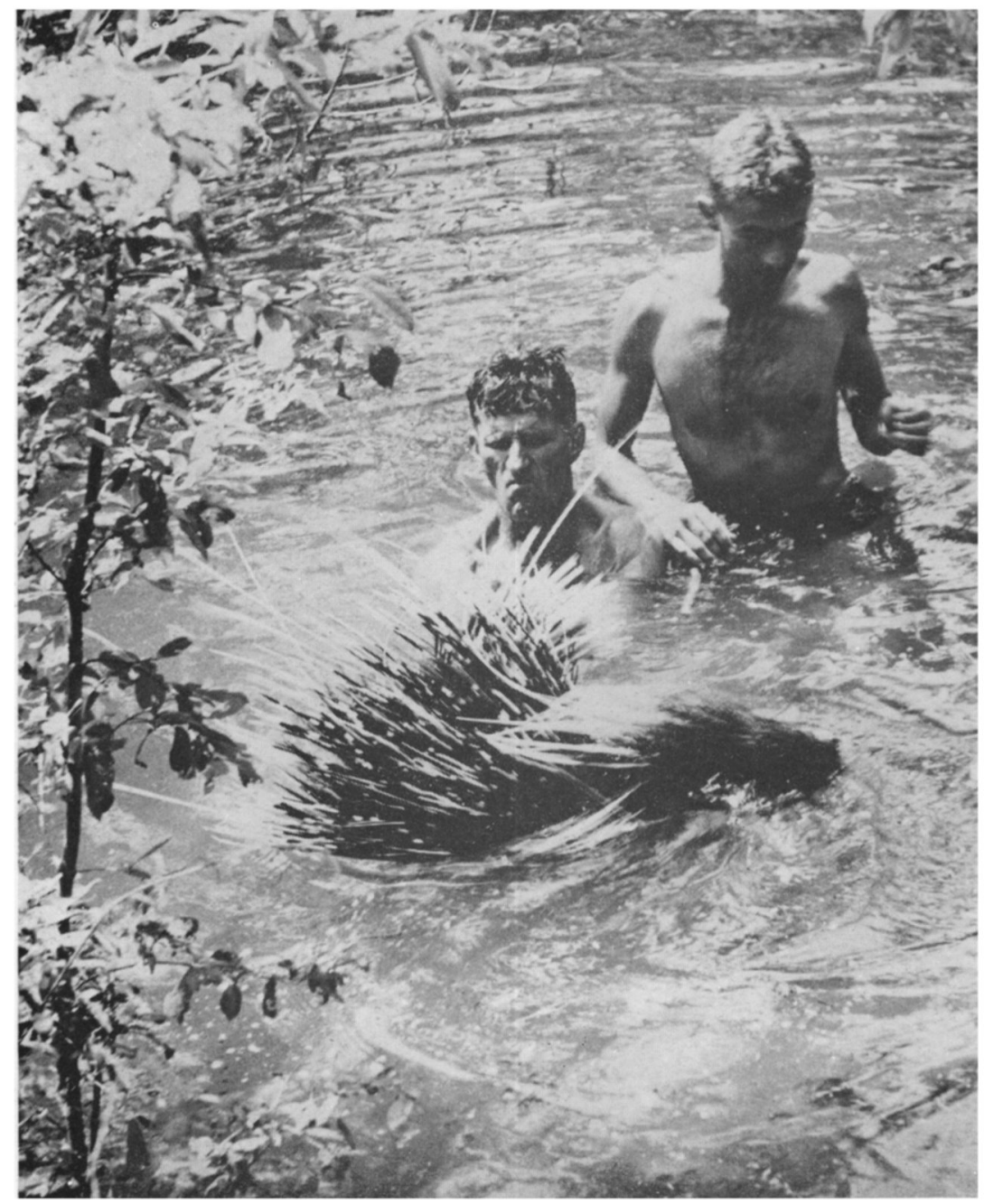

¿Courtesy of "Sunday Mail," Salishury, S. Rhodesia

OPLRATION NOAH. 


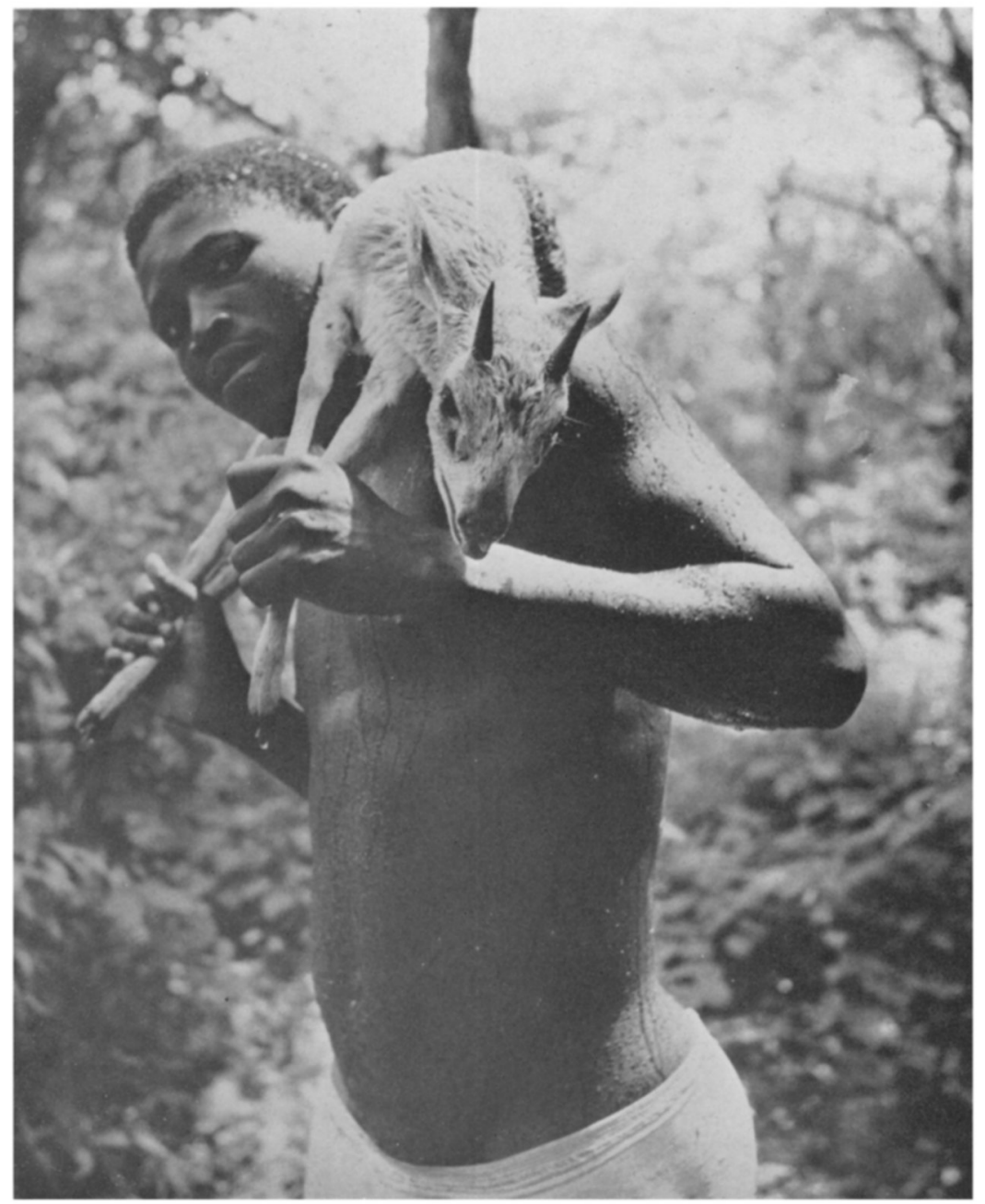

[Courtesy of "Sunday Mail," Salisbury, S. Rhodesia OPERATION NOAH. 


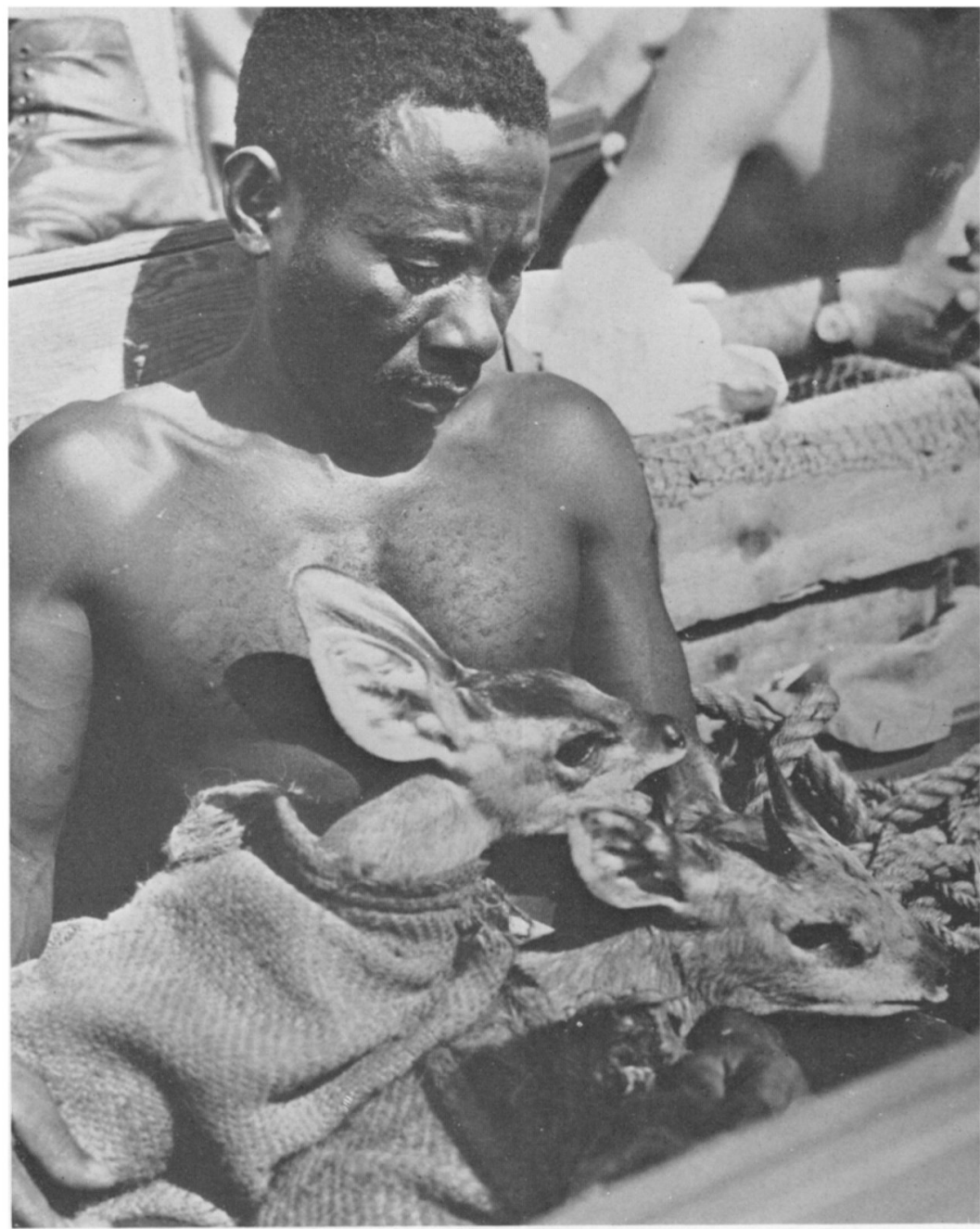

[Courtesy of "Sunday Mail," Salisbury, S. Rhodesia

OPIRATION NOAH. 